\title{
Safety and usefulness of composite grafts for total arterial myocardial revascularization: A prospective randomized evaluation
}

\author{
Claudio Muneretto, MD \\ Alberto Negri, MD \\ Jacopo Manfredi, MD \\ Alberto Terrini, MD \\ Giulia Rodella, MD \\ Suad EIOarra, MD \\ Gianluigi Bisleri, MD
}

See related editorial on page 782.

\footnotetext{
From the Department of Cardiac Surgery, University of Brescia Medical School, Brescia, Italy

Read at the Eighty-second Annual Meeting of The American Association for Thoracic Surgery, Washington, DC, May 5-8, 2002.

Received for publication June 4, 2002; revisions requested July 22, 2002; revisions received Aug 7, 2002; accepted for publication Aug 16, 2002.

Address for reprints: Claudio Muneretto, MD, UDA Cardiochirurgia-Spedali Civili, P.le Spedali Civili, 125123 Brescia, Italy (E-mail: munerett@master.cci.unibs. it).

J Thorac Cardiovasc Surg 2003;125:826-35

Copyright (C) 2003 by The American Association for Thoracic Surgery

0022-5223/2003\$30.00+0

doi: $10.1067 / \mathrm{mtc} .2003 .154$
}

Objectives: To evaluate the results of total arterial revascularization with composite grafts compared with the results of conventional coronary surgery, we enrolled 200 consecutive patient undergoing myocardial revascularization.

Methods: Patients were randomly assigned to 2 groups of 100 patients each: group 1 underwent total arterial revascularization, and group 2 received left internal thoracic artery on left anterior descending artery grafts plus additional saphenous vein grafts. The groups were comparable in terms of continuous and discrete variables and preoperative risk factors.

Results: There were no differences between group 1 and group 2 in terms of the number of grafted vessels (mean, 2.8 vs 2.9 , respectively), crossclamping time (mean, $38 \pm 7$ vs $40 \pm 6 \mathrm{~min}$, respectively), intensive care unit stay (mean, $25 \pm$ 8 vs $24 \pm 7$ hours, respectively), and hospital mortality (1\% in both groups) nor were there any differences in postoperative complications. At the mean follow-up of $12 \pm 4$ months, patients receiving total arterial revascularization (group 1) showed a better outcome in terms of angina recurrence (group 1 vs group 2: 2 vs 13 patients, $P=.007)$, need of percutaneous transluminal coronary angioplasty reintervention (group 1 vs group 2: 0 vs 8 patients, $P=.0012$ ), and actuarial freedom from cardiac events (group 1 vs group 2: $96 \%$ vs $67 \%, P=.006$ ). Angiography carried out in $72 \%$ in group 1 and in $68 \%$ in group 2 demonstrated a patency rate of $99 \%$ of saphenous vein grafts in group 1 and $89 \%$ of saphenous grafts in group 2.

Conclusions: Total myocardial revascularization with composite arterial grafts provided superior clinical results and improved patient outcome, even in the short term to midterm. Arterial conduit-related benefits were clearly evident with respect to recurrence of angina and a higher graft patency rate.

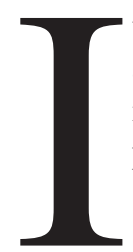

$t$ has been recognized worldwide that the use of the left internal thoracic artery (LITA) to bypass the left anterior descending coronary artery (LAD) is the gold standard in coronary surgery because it provides a superior graft patency rate and incremental long-term benefits. ${ }^{1-3}$

More recently, the use of multiple arterial conduits has been advocated to Cxtend those benefits to other coronary vessels, but contradictory clinical reports, ${ }^{4-6}$ anatomic limitations of pedicled internal thoracic arteries (ITAs), and doubtfulness about the functional properties of the radial and other arterial conduits made many surgeons reluctant to face the issue of total arterial revascularization. However, in the last few years, several studies have demonstrated that the use of 
multiple arterial grafts clearly improves the long-term outcome of patients undergoing coronary surgery. . $^{7-9}$

To overcome the anatomic limitations of ITAs and to expand the possibilities for full revascularization, the use of composite arterial grafts has been reported in an increasing number of studies, ${ }^{10-12}$ but few of them were prospective, and none were randomized.

We designed our study to evaluate the safety and usefulness of composite grafts to achieve total arterial revascularization and to compare results of total arterial revascularization with those provided by means of conventional coronary artery bypass graft (CABG) surgery. Outcome and variables, such as postoperative course, complications, death, recurrence of angina, graft occlusion, late cardiacrelated events, and reinterventions, were evaluated.

\section{Methods}

\section{Patient Population and Criteria Selection}

Between 1999 and 2001, we enrolled 200 patients undergoing isolated on-pump CABG; patients less than 50 years of age, with single-vessel disease, undergoing emergency operations, with left ventricular ejection fractions of less than $25 \%$, and with a EuroSCORE of greater than 7 were not included in the study.

The study protocol was approved by the institutional review board, which excluded patients younger than 50 years of age from this study because of ethical concerns about the use of saphenous vein grafts (SVGs) in this group of patients. All patients included in the study provided written informed consent relative to the type of operation.

Patients were randomly assigned to group $1(\mathrm{n}=100)$ or group $2(\mathrm{n}=100)$ : patients in group 1 underwent total arterial revascularization with composite grafts, whereas patients in group 2 underwent myocardial revascularization by means of LITA on LAD grafts plus additional SVGs.

The 2 groups were similar with respect to age (group 1 vs group 2: $67.06 \pm 9$ vs $68.03 \pm 8$ years, $P=.421$ ), sex (group 1 vs group 2 [male/female]: $73 / 27$ vs $75 / 25, P=.872$ ), and preoperative variables (Table 1). Composite arterial grafts in group 1 consisted of in situ LITA on LAD grafts plus right internal thoracic artery (RITA), radial artery (RA), or both, in Y/T grafts (Figure 1). The use of RITA was avoided in patients with insulin-dependent diabetes mellitus with clinical evidence of microangiopathies, chronic obstructive pulmonary disease with long-standing steroid treatment, and obesity (body mass index $>30$ ). The RA was harvested from the nondominant arm only in patients with negative Allen test results, palpable ulnar pulses, and near to normal oximetric plethysmography curves from the thumb during RA occlusion.

\section{Operative Technique}

Both ITAs were harvested as pedicled conduits, titanium clips were applied on side branches, electrocautery was avoided, and distal ITA bifurcations were systematically preserved.

The RA was harvested together with its satellite veins and connective tissue to minimize arterial wall damage and to prevent spasm. After heparinization, the ITAs and RA were divided distally, and an intraluminal injection of papaverine hydrochloride (200 $\mathrm{mg}$ of papaverine diluted in $100 \mathrm{~mL}$ of normal saline) was
TABLE 1. Comparison of preoperative clinical variables

\begin{tabular}{lccc}
\hline Variables & $\begin{array}{c}\text { Group 1 } \\
(\mathbf{n = 1 0 0 )}\end{array}$ & $\begin{array}{c}\text { Group 2 } \\
(\mathbf{n = 1 0 0 )}\end{array}$ & $\begin{array}{c}\boldsymbol{P} \\
\text { value }\end{array}$ \\
\hline Age (y) & & & \\
$\quad$ Mean & $67.06 \pm 9$ & $68.03 \pm 8$ & .421 \\
$\quad$ Range & $52-85$ & $50-84$ & \\
Sex (female) & 27 & 25 & .872 \\
Hypertension & 60 & 62 & .885 \\
COPD & 19 & 22 & .726 \\
Diabetes & 41 & 40 & 1 \\
Hypercholesterolemia & 40 & 38 & .885 \\
Obesity & 6 & 8 & .782 \\
PVD & 31 & 28 & .756 \\
Previous CVA & 5 & 8 & .566 \\
Redo surgery & 2 & 3 & 1 \\
Renal dysfunction & 3 & 5 & .718 \\
Unstable angina & 27 & 32 & .535 \\
Ejection fraction & & & \\
$\quad 30 \%-50 \%$ & 24 & 22 & .867 \\
$<30 \%$ & 5 & 6 & 1 \\
MI <90 d & 41 & 37 & .664 \\
Double-vessel disease & 26 & 29 & .751 \\
Euroscore & $4 \pm 1.9$ & $4.2 \pm 1.8$ & .446 \\
\hline
\end{tabular}

COPD, Chronic obstructive pulmonary disease; $P V D$, peripheral vascular disease; CVA, cerebrovascular accident; $M I$, myocardial infarction.

administered. When used as a free graft, the RA was divided proximally only before the related coronary anastomosis to avoid spasm caused by unnecessary storage.

Composite arterial $\mathrm{Y} / \mathrm{T}$ grafts were performed before cardiopulmonary bypass (CPB), and end-to-side anastomosis was carried out on the fascial side of the LITA with an 8-0 polypropylene running suture.

Standard CPB was instituted (mean flow, $2.5 \mathrm{~L} \times \min ^{-1} \times$ $\mathrm{m}^{-2}$ ) with moderate hypothermia $\left(33^{\circ} \mathrm{C}\right)$, and antegrade-retrograde oxygenated cold blood cardioplegia was used. The threshold degree of stenosis of coronary vessels was $70 \%$ for the use of the RA and $60 \%$ for ITAs.

Distal anastomoses on target coronary vessels were performed with 8-0 polypropylene running sutures for the arterial grafts and 7-0 sutures for SVGs; side-to-side anastomoses were done with a diamond-shaped configuration, and RA distal anastomoses were performed systematically as the last anastomosis.

Proximal anastomoses for SVGs were performed in standard fashion, and aortic anastomoses of the RA were performed with the interposition of a saphenous vein patch. Composite grafts were used in 3 different configurations (Figure 1) according to patients' characteristics, coronary anatomy, and target stenosis.

Type 1 configuration was used in cases of dominant (not occluded) right coronary artery (RCA) grafts because in those cases a composite graft totally dependent from the proximal LITA inflow might not be adequate to warrant blood supply for the entire coronary circulation.

Type 2 configuration was used in the case of nondominant or occluded RCAs in the presence of borderline stenosis of obtuse marginal branches or low run-off of the target coronary vessels. This configuration is based on sequential anastomosis that might maintain adequate flow through the RA or RITA, avoiding the 
A

TYPE 1
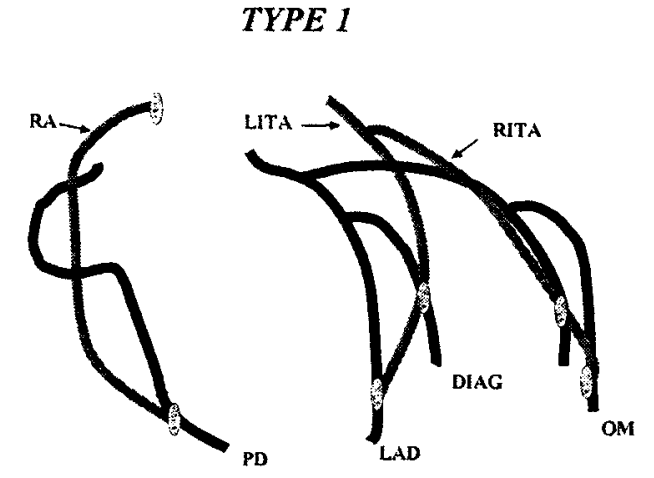

B

TYPE 2
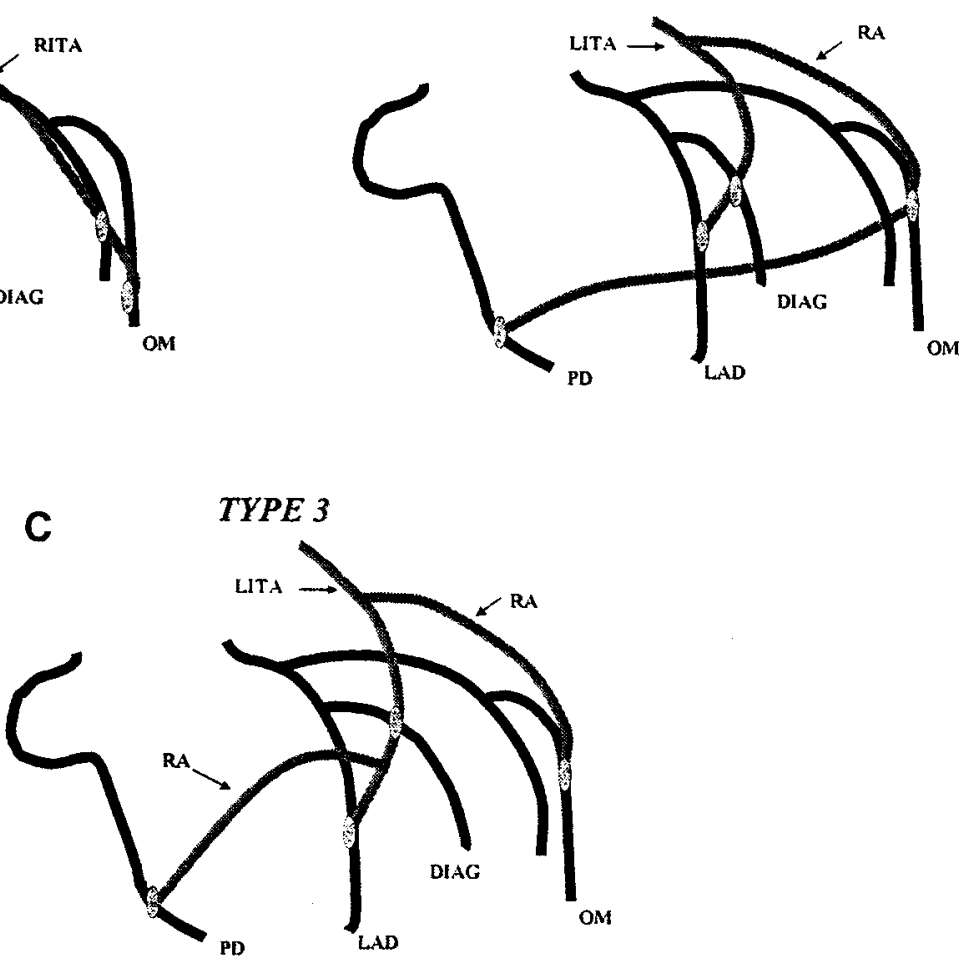

Figure 1. Composite arterial graft configuration technique. A, Type 1: the RITA is anastomosed to the in situ LITA as a $Y$ graft; as a free graft, the RA is anastomosed to the RCA. B, Type 2: the RA is anastomosed to the LITA as a $Y$ graft. C, Type 3: the 2 segments of the RA are anastomosed to the LITA in a double $Y$ graft fashion. PD, Posterior descending coronary; DIAG, diagonal.

threadlike phenomena or occlusion, even in the absence of critical stenosis or in the case of poor run-off of the coronary vessel. We considered type 2 configuration as the arrangement of first choice for the use of composite arterial grafts because it avoids RITA harvesting and aortic manipulation.

Type 3 configuration was considered as a rescue procedure when type 1 or 2 configuration failed.

The switch from type 1 to type 3 configuration was usually done in the presence of atheromatic lesions of the ascending aorta and when the posterior descending coronary artery had to be bypassed distally.

The switch from type 2 to type 3 configuration might be due to unfavorable anatomy of the posterolateral coronary vessels (convergence of the posterior descending coronary and obtuse marginal branches). However, when problems occur during side-to-side anastomosis on marginal branches, type 3 configuration might represent a key rescue procedure: the RA is divided at the level of the side-to-side anastomosis and can be turned easily into an end-to-side standard anastomosis. The remaining segment of the RA might be successfully used in most cases to reach the RCA branches.

In patients receiving RA grafts, oral diltiazem was given the day before the operation (60 $\mathrm{mg}$ every 8 hours). Intravenous diltiazem infusion (mean dose, $0.5-1.5 \mu \mathrm{g} \cdot \mathrm{kg}^{-1} \cdot \mathrm{min}^{-1}$ ) was administered throughout the operation and during the first 48 hours after the operation. Thereafter, diltiazem oral therapy $(\geq 120 \mathrm{mg} / \mathrm{d})$ was continued for at least 6 months.

\section{Patient Follow-up}

Follow-up data were collected during clinical visits at 1.5, 6, and 12 months after the operation and thereafter by telephone interview. Additional information was obtained from home physicians, patients' cardiologists, or both. Patients were assessed for survival and survival free from any cardiac-related event, such as death, myocardial infarction, recurrence of angina, percutaneous transluminal coronary angioplasty (PTCA), and surgical reintervention. Clinical symptoms of angina recurrence were confirmed by means of exercise testing and myocardial perfusion imaging (thallium201/technetium-99m).

\section{Data Analysis}

Values of continuous variables are expressed as means \pm SD. Preoperative and perioperative continuous variables were compared with the unpaired $t$ test and the Wilcoxon rank-sum test; the $\chi^{2}$ test was used for discrete variables. Actuarial event-free survival curves were estimated by using the Kaplan-Meier method (SAS/STAT Statistical Package, PROC LIFETEST. User's Guide, 
TABLE 2. Comparison of intraoperative variables between the 2 groups

\begin{tabular}{lccc}
\hline Variables & $\begin{array}{c}\text { Group 1 } \\
(\mathbf{n}=\mathbf{1 0 0})\end{array}$ & $\begin{array}{c}\text { Group 2 } \\
(\mathbf{n}=\mathbf{1 0 0})\end{array}$ & $\begin{array}{c}\boldsymbol{P} \\
\text { value }\end{array}$ \\
\hline No. of grafted vessels (mean) & $2.8 \pm 0.8$ & $2.9 \pm 0.6$ & .319 \\
Vessels-conduits & & & \\
$\quad$ LAD-LITA & 100 & 100 & .826 \\
Diag-LITA/RITA/RA/SVG & 19 & 13 & .311 \\
Cx-RITA/RA/SVG & 87 & 89 & .992 \\
RCA-RITA/RA/SVG & 74 & 88 & .345 \\
Crossclamping time (mean) & $38 \pm 7.4$ & $40 \pm 6.5$ & .336 \\
Total CPB time (mean) & $56 \pm 9$ & $81 \pm 7$ & .001 \\
\end{tabular}

Diag, Diagonal; $C X$, circumflex.

Version 8; SAS Institute, Cary, NC). Multivariate analysis was carried out by means of 2 different risk factor models. The Cox regression model was used to analyze the effects of all the potentially related variables, taking into account the time of occurrence of the dependent variable (angina recurrence, PTCA, and late death). Multivariate logistic regression analysis was carried out by using the presence, absence, or both, of graft occlusion as a dependent variable. For the Cox proportional hazard model, results are presented in terms of hazard ratios (HRs), HR 95\% confidence intervals (CIs), and levels of statistical significance in terms of $P$ value. Multivariate logistic regression analysis results are expressed in terms of $P$ values, odds ratios, and $95 \%$ CIs.

\section{Results}

\section{Preoperative Data}

Comparison of preoperative data and risk factors by means of univariate analysis showed no differences between the groups that were homogenous for continuous and discrete variables (Table 1). Distribution of patients' characteristics was similar to that reported from other authors, ${ }^{12-14}$ except for diabetes, the prevalence of which was particularly high in both groups (group 1 vs group 2: $40 \%$ vs $41 \%$ ).

\section{Perioperative Data}

There were no differences in the mean number of anastomoses nor were there any differences in terms of target vessels between the 2 groups (Table 2). Aortic crossclamping time was similar, whereas CPB duration was significantly higher in group 2 as a consequence of the proximal SVG anastomoses (Table 2).

The conduit-type geometry of composite arterial grafts are described in Figure 1: type 1 geometry was performed in 38 patients, and type 2 and type 3 geometry were performed in 54 and 8 patients, respectively.

There was one (1\%) hospital death in each group because of sudden intractable ventricular fibrillation (without any evidence of prearrhythmic hemodynamic abnormalities, electrocardiographic abnormalities, or arterial graft spasm) in group 1 and to prolonged mechanical ventilation leading to sepsis in group 2. No significant differences were ob-
TABLE 3. Comparison of postoperative variables and complications

\begin{tabular}{lccc}
\hline Variables & $\begin{array}{c}\text { Group 1 } \\
(\mathbf{n}=\mathbf{1 0 0})\end{array}$ & $\begin{array}{c}\text { Group 2 } \\
(\mathbf{n}=\mathbf{1 0 0})\end{array}$ & $\begin{array}{c}\boldsymbol{P} \\
\text { value }\end{array}$ \\
\hline ICU stay (h) & $25 \pm 8$ & $24 \pm 7$ & .348 \\
Mechanical ventilatory & $9 \pm 6.5$ & $11 \pm 7.4$ & .044 \\
$\quad$ support (h) & $4.8 \pm 1.9$ & $5 \pm 2$ & .469 \\
Postoperative stay (d) & 1 & 1 & .477 \\
Hospital mortality & 23 & 22 & 1 \\
Atrial fibrillation & 35 & 37 & .883 \\
Blood transfusion & 3 & 2 & 1 \\
Pneumothorax & 1 & 2 & 1 \\
Reoperation for bleeding & 3 & 3 & .678 \\
Acute renal failure & 0 & 1 & 1 \\
CVA & 1 & 2 & 1 \\
IABP support & 1 & 2 & 1 \\
MI & 2 & 3 & 1 \\
Prolonged mechanical & & & \\
$\quad$ ventilation & 1 & 0 & 1 \\
Intractable arrhythmia & 1 & 1 & .477 \\
Sternal dehiscence & 0 & 1 & 1 \\
Intestinal ischemia & &
\end{tabular}

ICU, Intensive care unit; CVA, cerebrovascular accident; IABP, intra-aortic balloon pump; $M I$, myocardial infarction.

served between the groups in terms of intensive care unit and postoperative stay; mechanical ventilatory support was longer in group 2 (Table 3 ).

Univariate analysis showed no differences between the groups with respect to postoperative complications (Table $3)$. Even patients undergoing double-ITA harvesting ( $\mathrm{n}=$ 40) did not show any differences in terms of postoperative complications when compared with group 2 (blood transfusion: double-ITA group vs group $2,37.5 \%$ vs $37 \%, P=$ .883; prolonged mechanical ventilation: double-ITA group vs group $2,2.5 \%$ vs $3 \%, P=1$; sternal dehiscence: doubleITA group vs group $2,2.5 \%$ vs $1 \%, P=.477$ ).

\section{Late Outcome and Survival}

At the mean follow-up of $12 \pm 4$ months, recurrence of angina was significantly lower in group 1 (group 1 vs group 2: 2 vs 13 patients, $P=.007$ ).

Patients in group 1 showed a better outcome also in terms of all other cardiac-related events when compared with patients in group 2. The incidence of PTCA reinterventions was significantly lower in group 1 (group 1 vs group 2: 0 vs 8 patients, $P=.012$ ). Late occurrence of myocardial infarction and cardiac-related death were also lower in group 1, but differences between the groups did not reach a significant statistical value (myocardial infarction: group 1 vs group 2,0 vs 2 patients, $P=.477$; late death: group 1 vs group 2,1 vs 3 patients, $P=.641$ ).

Angiography was carried out in all symptomatic patients and at random in 72 patients of group 1 and in 68 patients of group 2: graft patency was $99 \%$ of SVGs in group 1 and 


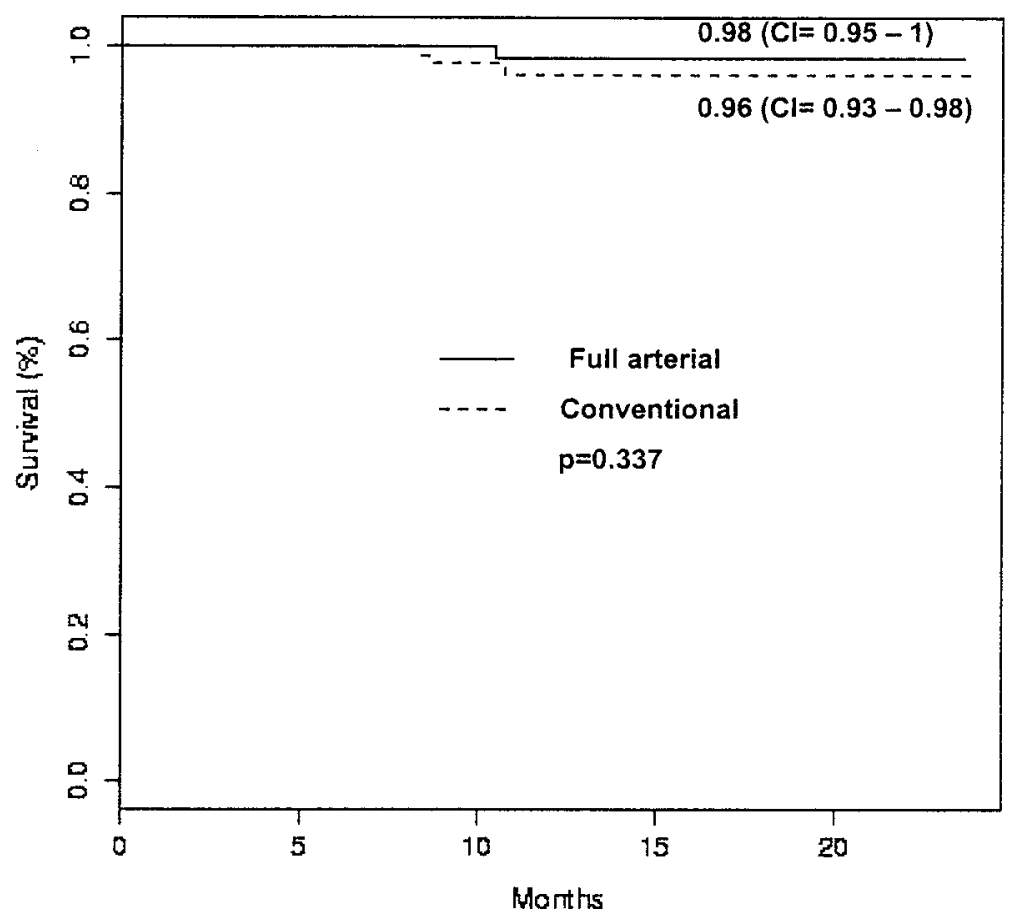

Figure 2. Comparison of overall survival in patients receiving total arterial revascularization (full arterial) versus conventional CABG surgery (conventional).

$89 \%$ of SVGs in group 2 (15 SVGs occluded). Patency of LITA (in group 1 and group 2) and RITA was 100\%, with no graft or $\mathrm{Y}$ anastomoses occluded. The RITA became threadlike in $3(7.5 \%)$ patients: in all of them, anastomosis was carried out on obtuse marginal branches with a borderline stenosis (approximately 70\%). None of those patients had symptoms.

There was only one arterial conduit occluded in group 1 (RA grafted on obtuse marginal branch), whereas among 137 SVGs in group 2, 15 conduits were occluded, with an overall SVG patency rate of $89 \%$. The patency of SVGs used to bypass the circumflex system and the RCA was 91.6\% (76/83 SVGs) and 85.2\% (46/54 SVGs), respectively.

Actuarial survival at 20 months was similar in the 2 groups (Figure 2); however, patients in group 1 had a significantly better actuarial survival free from any cardiac event (Figure 3). The presence of diabetes had a tremendous effect on the outcome, with a significant reduction of actuarial survival free from late events (Figure 4).

We attempted to use the Cox proportional hazard model to analyze the effects of the different potentially related variables (presence of SVGs, diabetes, age $>70$ years, hypertension, obesity, female sex, and EuroSCORE), taking into account the time of occurrence of the dependent variables (angina, need of PTCA, and late death). Diabetes and the presence of SVGs (group 2) were identified as incre- mental risk factors for recurrence of angina (diabetes: $P=$ $.0018, \mathrm{HR}=25.92,95 \% \mathrm{CI}=3.35-200.35$; SVGs: $P=$ $.0088, \mathrm{HR}=7.95,95 \% \mathrm{CI}=1.68-37.54)$, but the small number of events made the hazard model unreliable, as indicated by the extremely wide CIs. In addition, diabetes was also an incremental risk factor for PTCA reintervention $(P=.04)$. The cumulative hazard of angina recurrence showed a significantly higher risk (7.95 times) in group 2 (Figure 5).

Multivariate logistic regression analysis with the presence or absence of graft occlusion as a dependent variable and the variables listed in Table 1 as independent variables identified diabetes $(P=.0006$, odds ratio $=42.34,95 \%$ $\mathrm{CI}=5.11-350.86)$ and $\mathrm{SVGs}(P=.0019$, odds ratio $=$ $30.04,95 \% \mathrm{CI}=3.52-255.81)$ as predictors for graft occlusion, but because of the small number of events, the wide CIs made the multivariate regression analysis unreliable.

\section{Discussion}

The ITA is recognized worldwide as the graft of choice for myocardial revascularization because of its favorable properties, and the use of the LITA to bypass the LAD has been able to steadily improve the results of CABG surgery across time. ${ }^{1-3}$

Consequently, the use of bilateral ITAs has been advocated to extend benefits to the circumflex artery and RCAs, but contradictory clinical reports, ${ }^{4-6}$ concerns about sternal 


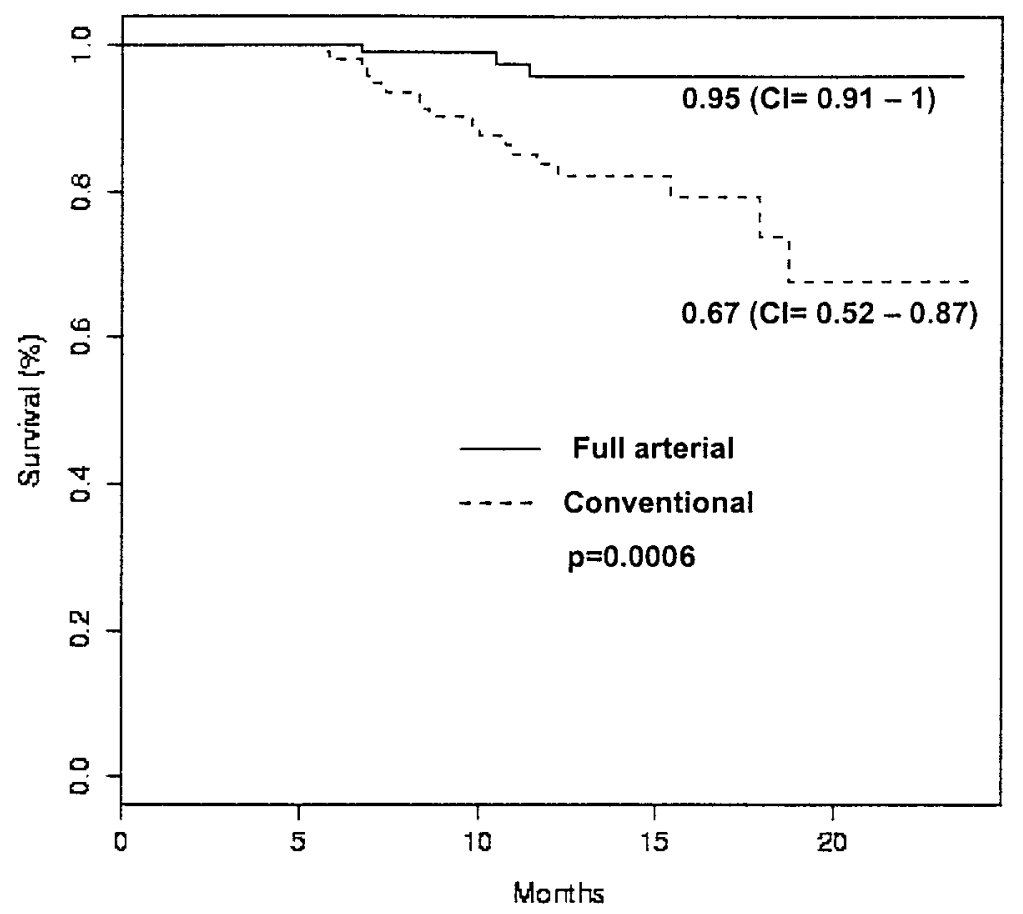

Figure 3. Comparison of event-free survival (nonfatal myocardial infarction, angina recurrence, graft occlusion, need of PTCA reintervention, and late death) in patients receiving total arterial revascularization (full arterial) versus conventional CABG surgery (conventional).

devascularization, and the anatomic limitation of the RITA made many surgeons skeptical about the advantages of double ITAs.

In an attempt to overcome technical problems related to the use of the RITA and to reduce the rate of bilateral ITA harvesting, alternative arterial conduits have been studied. ${ }^{15-17}$

Among them, the RA was the conduit most extensively studied and used. ${ }^{15,18-22}$ Today, the RA is more frequently used in composite arterial grafts because this technique overcomes the pitfalls of aortic anastomosis, avoiding unnecessary ascending aorta manipulation.

Our study was designed as a prospective randomized comparison to avoid selection bias and to allow comparison of treatment strategies of equal patient subsets. The study population was almost unselected, and $75 \%$ of the patients entered into the study underwent CABG surgery in the same study period with few exclusion criteria. Patients less than 50 years of age were excluded for ethical reason related to the use of SVGs. High-risk patients (EuroSCORE of $>7$ and left ventricular ejection fraction of $<25 \%$ ) were not included because the number of patients in our study was insufficient to warrant a homogenous distribution of patients at high risk.

Our study had 2 main objectives. The first objective was to assess the safety of total arterial revascularization with composite grafts in comparison with conventional revascularization. This study showed that early morbidity and mortality were nearly identical in the 2 groups. Patients undergoing full arterial revascularization did not show any increase in postoperative complications, such as intraoperative myocardial infarction, bleeding, sternal dehiscence, blood transfusion, mechanical ventilatory support, and intensive care unit stay. The operative time was absolutely comparable between the groups, whereas CPB duration was significantly shorter in group 1 because of the reduced number of proximal aortic anastomoses. The mean number of grafted vessels was similar between the groups, indicating that composite arterial grafts allowed a full revascularization.

The second objective of our study was to demonstrate the usefulness of full myocardial revascularization with composite arterial grafts, even in the short term to midterm, because the majority of previous studies demonstrated incremental benefits of multiple arterial grafts only in the long term. ${ }^{7,8,12,23}$ However, almost all those studies were retrospective and therefore at risk of bias for the selection of treatment and equal patient subsets. Our randomized study showed that total arterial revascularization with composite arterial grafts clearly improved the midterm outcome in terms of angina recurrence, PTCA reintervention, and freedom from cardiac-related events. Patients undergoing 


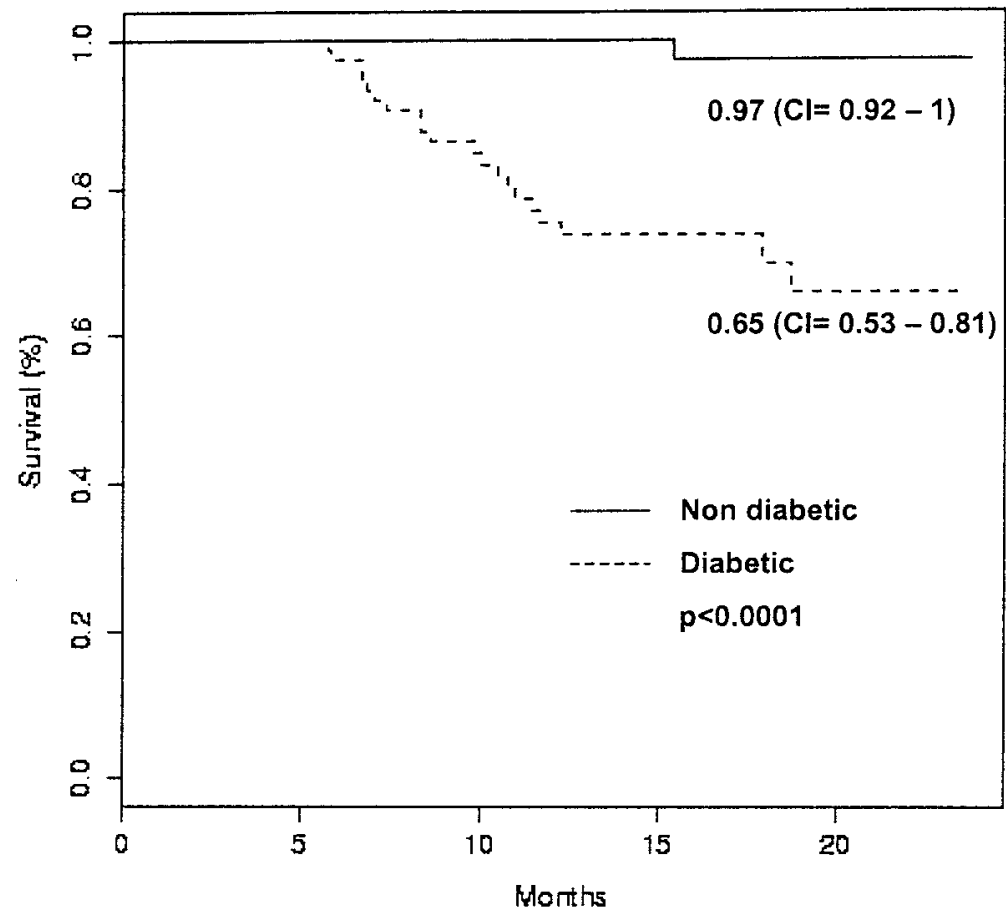

Figure 4. Comparison of event-free survival (nonfatal myocardial infarction, angina recurrence, graft occlusion, need of PTCA reintervention, and late death) in diabetic versus nondiabetic patients.

CABG surgery with SVGs (in addition to the LITA on the LAD) had a 7.95 times higher risk of development of recurrence of angina.

Angiography confirmed the clinical evidence, showing a significantly lower graft patency rate in patients receiving SVGs. The patency of SVGs was similar to that previously reported. Moreover, the arterial conduit patency rate of $99 \%$ suggests that the use of composite arterial grafts not only expands the possibilities for full arterial revascularization but might improve clinical and angiographic results.

Angiography in our study also demonstrated that the RA, when used as a composite graft, might offer an excellent midterm patency rate comparable with that of the RITA, regardless of the location of the target vessel.

Among patients treated with RA grafts, there was no clinical evidence or angiographic demonstration of early or late arterial spasm, suggesting that preoperative, intraoperative, and postoperative $\mathrm{Ca}^{++}$-channel blocker treatment was effective to control RA vasoreactivity.

We believe that the use of composite arterial conduits might play an important role in the reduction of pitfalls associated with the use of in situ ITAs. This study evidenced several benefits of total arterial revascularization that were not evident in many other reports. In particular, those benefits were evident in the short term to midterm, whereas almost all comparison of arterial versus conventional grafts was able to demonstrate differences only in the long term (up to 10-15 years). This fact might be related to the extremely high prevalence of diabetes in our population $(40.5 \%)$. Diabetes has been identified as an independent predictor and incremental risk factor for cardiac-related events and both overall and late cardiac death. ${ }^{7,8,24}$ When we analyzed the effect of diabetes on cardiac-related morbidity, we found tremendous differences in terms of actuarial survival free from any cardiac events when the diabetic patients where compared with the remaining population (Figure 4).

In addition, our results showed that diabetes negatively affected the outcome only of the patients treated with SVGs. In other words, patients with total arterial revascularization had the same outcome, regardless of the presence of diabetes. The follow-up of these patients will be continued at 5 and 10 years to confirm, in the long term, the superior benefits of total arterial revascularization when compared with those of conventional surgery.

The characteristics of patients undergoing CABG surgery have been steadily worsening during the last 10 years. Today, patients undergoing CABG are not only older, with a higher number of preoperative risk factors, but they have undergone multiple PTCA procedures before surgical intervention. Coronary artery characteristics also worsened, and today, the higher degree of atheromatous degeneration results in an important reduction of both coronary artery diameter and run-off. In these circumstances the use of 


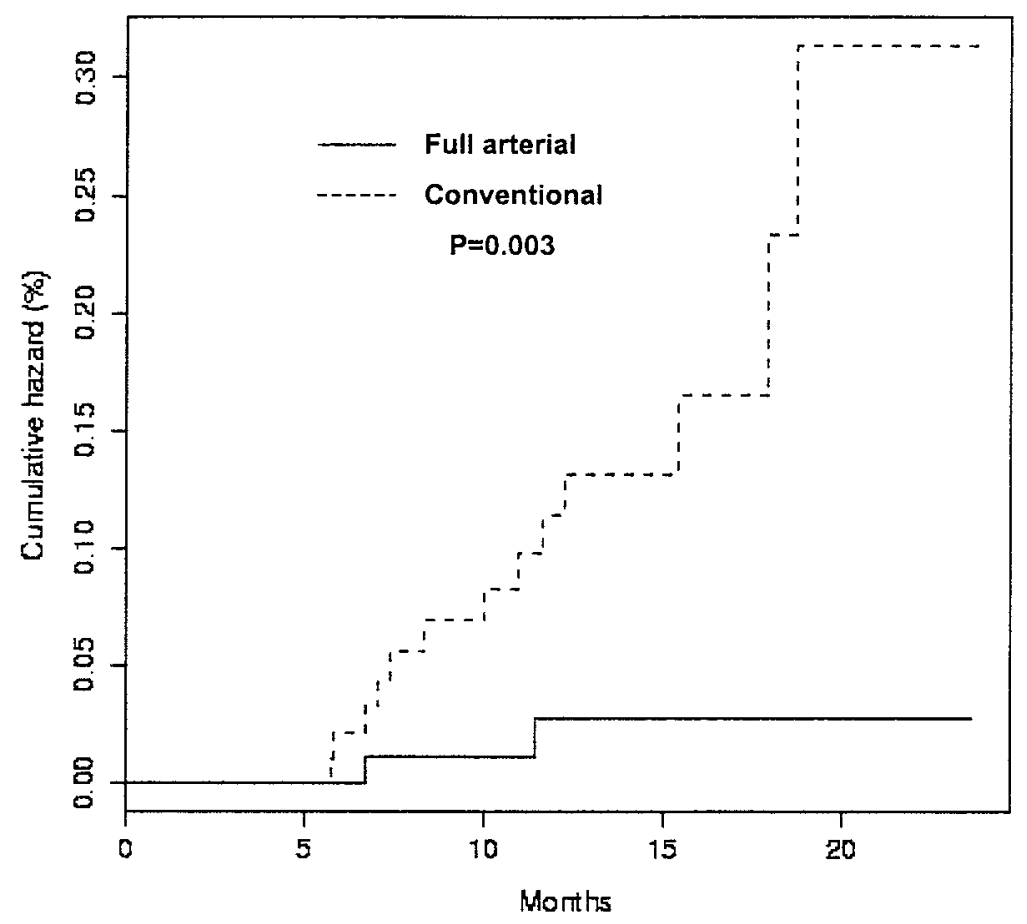

Figure 5. Cumulative hazard of angina recurrence for patients receiving total arterial revascularization (full arterial) versus conventional CABG surgery (conventional).

SVGs might be associated with a significantly higher risk of graft occlusion, even in the short term to midterm. This means that the effect of full arterial revascularization on the outcome of patients undergoing $\mathrm{CABG}$ might be more evident than previously reported.

In conclusion, this study provides additional evidence that the use of composite arterial grafts is safe and useful to achieve full arterial revascularization. The study clearly indicates that total myocardial revascularization provides superior clinical results when compared with conventional CABG, even in the short term to midterm. Arterial conduitrelated benefits were evident and significant in terms of a reduced recurrence of angina and graft patency rate and a lower incidence of late cardiac events.

\section{References}

1. Lytle BW, Looop FD, Cosgrove DM, Ratliff NB, Easley K, Taylor PC. Long-term (5 to 12 years) serial studies of internal mammary artery and saphenous vein coronary bypass grafts. $J$ Thorac Cardiovasc Surg. 1985;89:248-58.

2. Loop FD, Lytle BW, Cosgrove DM, et al. Influence of the internal mammary artery graft on 10-year survival and other cardiac events. N Engl J Med. 1986;314:1-6.

3. Cameron A, Davis KB, Graeen G, Schaff HV. Coronary bypass surgery with internal thoracic artery grafts: effects on survival over a 15 year period. $N$ Engl J Med. 1996;334:216-9.

4. Kouchoukos NT, Wareing TH, Murphy SF, Pelate C, Marshall WG Jr. Risks of bilateral internal mammary artery grafting. Ann Thorac Surg. 1990;49:210-9.
5. Galbut DL, Traad EA, Dorman MJ, et al. Seventeen year experience with bilateral internal mammary artery grafts. Ann Thorac Surg. 1990;49:195-201.

6. Barner HB, Standeven JW, Reese J. Twelve-year experience with internal mammary artery for coronary bypass. J Thorac Cardiovasc Surg. 1985;90:668-75.

7. Pick AW, Orszulak TA, Anderson BJ, Schaff HV. Single versus bilateral internal mammary artery graft: 10 year outcome analysis. Ann Thorac Surg. 1997;64:599-605.

8. Lytle BW, Blackstone EH, Loop FD, et al. Two internal thoracic artery grafts are better than one. J Thorac Cardiovasc Surg. 1999;117: 855-72.

9. Barra JA, Mondine P, Bezon E, Mahalab A, Rukbi I, Braesco J. Revascularisation des arteres coronaires. Reimplantation en $\mathrm{Y}$ de artere mammaire interne droite dans l'artere mammaire interne gauche. Presse Med. 1991;20:423-5.

10. Tector AJ, Amundsen S, Schmahl TM, Kress DC, Peter M. Total revascularization with T grafts. Ann Thorac Surg. 1994;57:33-9.

11. Barra JA, Bezon E, Mansourati J, Rukbi I, Mondine P, Youssef Y. Reimplantation of the right internal thoracic artery as a free graft into the left in situ internal thoracic artery ( $\mathrm{Y}$ procedure): one-year angiographic results. J Thorac Cardiovasc Surg. 1995;109:1042-8.

12. Calafiore AM, Contini M, Vitella G, et al. Bilateral internal thoracic artery grafting: long-term clinical and angiographic results of in situ versus Y grafts. J Thorac Cardiovasc Surg. 2000;120:990-8.

13. Royse A, Royse CF, Raman JS. Exclusive Y-graft operation for multi-vessel coronary revascularization. Ann Thorac Surg. 1999;68: $1612-8$.

14. Borger MA, Cohen G, Buth KJ, et al. Multiple arterial grafts. Radial versus right internal thoracic artery. Circulation. 1998;98(Suppl):II7-14.

15. Acar C, Jebara VA, Portoghese M, et al. Revival of the radial artery for coronary artery bypass grafting. Ann Thorac Surg. 1992;54:65260. 
16. Suma H, Wanibuchi J, Terada Y, Fukuda S, Takayama T, Furuta S The right gastroepiploic artery graft: clinical and angiographic midterm results in 200 patients. J Thorac Cardiovasc Surg. 1993;105: 615-23.

17. Grandjean JG, Boonstra PW, den Heyer P, Ebels T. Arterial revascularization with the right gastroepiploic artery and internal mammary arteries in 300 patients. J Thorac Cardiovasc Surg. 1994;107:1309-16.

18. Carpentier A, Guermonprez JL, Deloche A, Frechette C, Dubost C The aorta to coronary radial artery bypass graft: a technique avoiding pathological changes in grafts. Ann Thorac Surg. 1973;16:111-21.

19. Chen AH, Nakao T, Broadman RF, et al. Early postoperative angiographic assessment of radial grafts used for coronary bypass grafting. J Thorac Cardiovasc Surg. 1996;111:1208-12.

20. Reyes AT, Frame R, Broadman RF. Technique for harvesting the radial artery as a coronary artery bypass graft. Ann Thorac Surg. 1995;59:118-26.

21. Possati GF, Gaudino M, Alessandrini F, et al. Midterm clinical and angiographic results of radial artery grafts used for myocardial revascularization. J Thorac Cardiovasc Surg. 1998;116:1015-21.

22. Sundt TM 3rd, Barner HB, Camillo CJ, Gay WA Jr. Total arterial revascularization with an internal thoracic artery and radial artery $\mathrm{T}$ graft. Ann Thorac Surg. 1999;68:399-404.

23. Kurlansky PA, Traad EA, Galbut DL, Zucker M, Ebra G. Efficacy of single versus bilateral mammary artery grafting in women: a longterm study. Ann Thorac Surg. 2001;71:1949-58.

24. Buxton BF, Komeda M, Fuller JA, Gordon I. Bilateral internal thoracic artery grafting may improve outcome of coronary artery surgery: risk-adjusted survival. Circulation. 1998;98(Suppl):II-1-6.

\section{Discussion}

Dr Thoralf M. Sundt (Rochester, Minn). The study just presented joins a growing body of literature documenting the safety of complete arterial revascularization using a composite conduit technique. Dr Muneretto and his colleagues should be proud of this contribution. Their results are outstanding. The authors have gone a step beyond previous studies in two important ways. First, they have examined the impact of complete arterial revascularization, not just the impact of a second arterial graft, on outcomes. Second, they have done so in the context of a prospectivly randomized study. The authors should be proud of the design of their study. However, it is important to remember, just as Professor Turina noted earlier, that a randomized study design does not guarantee freedom from selection bias. It just shifts the potential bias to the point of entry into the trial. In the study, patients undergoing emergency operation, those with an ejection fraction less than $25 \%$ and those with a EuroSCORE profile higher than 7 were excluded. This leads to my first question. Is this study group representative of your general practice? During the study interval, what percentage of patients were entered into the study?

Dr Muneretto. Thank you, Dr Sundt, for your kind remarks. We designed our study in an attempt to answer three main questions. First, whether the use of a composite arterial graft is a safe technique in coronary surgery. Then we evaluated whether this technique is useful to achieve a full arterial revascularization in all patients. Finally, we studied the impact of full arterial revascularization on outcome at short and midterm. Our randomized evaluation was designed to answer those questions avoiding selection bias.

Of course I fully agree with you about the fact that a randomized study may not completely eliminate selection bias that could be shifted to the entry point of the trial. This did not happen in our study in which the study population was relatively unselected. As you noted, some patients were excluded: patients less than 50 years of age because of ethical reasons (related to the use of the SVGs) and high risk patients (left ventricular ejection fraction less than 25, EuroSCORE higher than 7) because the number of those patients was very small and insufficient to guarantee an equal distribution between the groups. An unbalanced high-risk patient distribution could have affected reliability of the study. However, ut except for these few exclusions, more than $85 \%$ of patients undergoing coronary surgery in the same study period were enrolled in the trial.

Dr Sundt. Thank you. My second question relates to the management of coronary arteries with only moderate stenoses. What is your threshold stenosis for grafting-50\%, 70\%? Would you graft a target vessel with a 50\% stenosis with an artery, a vein, or leave it ungrafted? In addition, you stated in your manuscript that of the three grafting strategies, the ITA radial artery $\mathrm{T}$ graft was your preferred approach when the stenosis of the obtuse marginal was "less severe." In our experience in St Louis, Rick Barner and I found that it was in just this particular circumstance that there was risk of occlusion of the proximal limb of the $\mathrm{T}$ graft-the segment between the ITA and the first anastomosis. Did you see such occlusions or string signs?

Dr Muneretto. It is a hard task trying to identify a cutoff value of threshold stenoses for grafting. In fact, the same degree of stenosis may cause quite different coronary flow impairment depending on type, diameter, and location of the coronary vessel, left ventricular mass, stress indices, and many other factors. In addition, some proximal stenoses may be life-threatening, and the problem becomes even more complex in patients with unstable angina in which the degree of the stenosis is a dynamic process. I can only answer that we are more aggressive in patients with unstable angina and in those with a proximal lesion of the RCA greater than 50\%. Usually we graft these patients. Conversely, we try to respect stenosis of the circumflex and marginal branches less than $70 \%$, especially if those vessels are likely to be treated by angioplasty. Our approach for less than severe stenosis of marginal branches is basically a Y graft based on multiple side-to-side anastomoses. I am aware of your outstanding experience in the use of composite grafts: you reported in The Annals of Thoracic Surgery in 1999 and 2001 that RA patency was sensitive to both location and target stenosis. We share your opinion and we took advantages of your observations in our experience. We do believe that in case of borderline stenosis of marginal branches the RITA in Y graft should be preferred (instead of the RA) because this graft seems to be less sensitive to competitive flow: it may become a threadlike artery, but this functional and reversible change allows the graft to maintain its patency.

Dr Sundt. Finally, you have failed to show any impact of complete arterial revascularization on survival. This is not a surprise as the follow-up is short and the numbers are small. In my view, given the remarkable effectiveness of current medical, interventional cardiologic, and surgical treatment of ischemic heart disease, one needs the kinds of numbers only achievable at The Cleveland Clinic and the kinds of statistics only comprehensible to Dr Blackstone to demonstrate such a difference. This is also the case with angioplasty versus surgery trials: it is difficult, if not impossible, to demonstrate a difference in survival. On the other hand, you have shown a remarkable difference in recurrent angina in a very short time interval. This is an exciting finding as we try 
to improve the results of surgical revascularization. A reduction in recurrent angina is exactly what we should hope to achieve with complete arterial revascularization. It is an important clinical end point. Should we then expand our indications for complete arterial revascularization? Most of us have considered applying arterial grafts only to young patients at risk for late graft occlusion, looking at the long run. However, if this marked early benefit is valid, the argument really applies to everyone. Should everyone get arteries?

Dr Muneretto. I would say yes. I do believe that the indications for full arterial revascularization should be expanded even in older patients. A randomized clinical trial comparing results of full arterial revascularization versus conventional surgery in patients older than 75 years of age is underway at our institution, and we strongly endorse proceeding with a multicenter trial in collaboration with experienced centers to confirm our data in a larger cohort of patients.

Dr Robert A. Dion (Leiden, The Netherlands). I am a warm supporter of arterial grafting anyway. My question is more a technical one. Why are you only pleading for the Y graft? What is the place in your practice for a bilateral pedicled graft? In the majority of the patient population that we see, we still can use the RITA and LITA without making them free. If you have decided to just restrict your use of ITAs to the Y construction, do you perform systematically a preoperative angiography of the LITA?

Dr Muneretto. Thank you, Dr Dion, for your interesting question that allow me to discuss an important aspect of this technique. At the beginning of our experience in full arterial revascularization, we used in situ bilateral ITA grafts with the addition of the RA as a free graft if required. We introduced the use of composite arterial grafts to overcome some anatomic limitations of in situ ITAs. However, the use of composite grafts has been steadily expanded because this technique not only overcomes anatomic limitations of in situ grafts but also reduces technical pitfalls; it is more reproducible and easier to teach to young surgeons. In other words, composite arterial graft technique is easy and requires less experience than the in situ graft technique.

Dr Dion. Did you perform a preoperative angiography of the LITA?

Dr Muneretto. No, we did not. We routinely carried out an echo Doppler evaluation of the supra-aortic vessels, and angiography was restricted to a few patients with stenosis.

Dr Richard F. Brodman (New York, NY). You make a very good point that we all are aware of: when we do coronary bypass surgery, some of the grafts are for survival and others are quality of life. You have demonstrated very nicely that multiple arterial grafts improve the quality of life early after CABG.. With regard to your early patency data, you show a decrease in patency in the vein graft group compared with the arterial bypass group. Is that due to a selection bias since you had very little angina in the all-arterial bypass group and symptoms in the vein graft group? Your findings differ from other studies in which early vein graft patency is the same as arterial graft patency.
Dr Muneretto. Thank you very much for your question, Dr Brodman. We presented a prevalence of diabetes in our population that was considerably higher when compared with other previous studies, and we believe that this fact may affect early patency of SVGs. In addition, patients referred to our institution, even if diabetic, are usually treated with repeated angioplasty in first instances. As a consequence, many of those patients may have a poor coronary anatomy and runoff at the time of operation. This fact may have been a bias influencing the results. However, the overall patency of SVGs in our study (89\% overall, with $91 \%$ patency on obtuse marginal district and a little bit less for the distal RCA) does not differ from previous reports in the literature, and the significant differences in terms of patency between the groups were mainly related to the excellent patency of the arterial grafts.

Dr Brodman. I just have one follow-up comment. I have been using RAs routinely in my practice since 1993, and I have always believed that you should do the best operation on a patient irrespective of age. I have not used age as a contraindication to the use of an RA graft. My oldest patient was 95 when I performed her operation.

Dr Antonio M. Calafiore (Chieti, Italy). Looking at your data, you report a high number of patients with diabetes. Do you think that this incidence affected the results in terms of patency rate and event-free survival. In other words, if you evaluate your data without this group of patients, will you have the same results?

Dr Muneretto. Thank you very much, Dr Calafiore. Yes, we did. As already pointed out, diabetes was highly prevalent in our study population and had a tremendous deleterious impact on the outcome of patients, particularly on those treated with SVGs. However, even when diabetic patients were excluded from the analysis, patients receiving arterial grafts showed a better outcome than those receiving SVGs. In other words, the presence of diabetes worsened the results and negatively affected the outcome, especially in patients receiving SVGs, thus making the difference between the groups more striking.

Dr Craig R. Smith (New York, NY). I have a quick technical question. I was surprised, maybe even shocked, to hear that you prefer to use the RA to construct the conduits before exhausting all the possibilities of the ITAs. Can you explain your bias in favor of that?

Dr Muneretto. Thank you, Dr Smith. First, multiple side-toside anastomoses with the RA are quite easy when compared with multiple side-to-side anastomoses with the RITA, at least in our experience. The second concern is related to the duration of the operation. The simultaneous harvesting of the RA and ITA reduces the duration of the surgical procedure with clinical and economical benefits. In addition, it could be safely used in all patients regardless of the presence of diabetes, chronic obstructive pulmonary disease, and other risk factors. Our experience seems to confirm that early patency of RA grafts is absolutely similar to that of the ITAs. 